\title{
Economics of Improved Reproductive Performance in Dairy Cattle ${ }^{1}$
}

\author{
Albert de Vries, Jessika van Leeuwen, William W. Thatcher ${ }^{2}$
}

\section{Introduction}

The reproductive performance of a dairy herd has a significant effect on the profitability of that herd. Common measures of reproductive performance are days to first service, days to conception, calving interval, services per conception, conception rate, estrus detection rate, and pregnancy rate.

Pregnancy rate is a good overall measure of reproductive performance. It is calculated as the number of cows that got pregnant divided by the number of cows that were eligible to get pregnant. It is a measure of the speed at which cows get pregnant after the voluntary waiting period. Pregnancy rate can be estimated as the conception rate $\mathrm{x}$ estrus detection rate if those are known. For example, a 50\% estrus detection rate and a $40 \%$ conception rate result in a $50 \% \times 40 \%=20 \%$ pregnancy rate; every 4 out of 5 eligible open cows did not get pregnant when they could have. An analysis of all DHIA Holstein herds in Florida and Georgia showed that average pregnancy rates in 1998-2000 were 17\%, but with considerable seasonal variation (Figure 1).
This fact sheet provides some estimates of the economic benefits of improved reproductive performance through increasing pregnancy rates in dairy herds. After a short literature review, the fact sheet focuses on estimates under conditions in Florida. At the herd level, the economic value of an improvement in pregnancy rate and the cost of an additional day open are estimated. This is done for both an overall increase of pregnancy rate and an increase of first service pregnancy rate. In addition, the fact sheet presents some estimates of the maximum that can be spent on a reproductive program to obtain increases in first service pregnancy rates. At the cow level, the values of a new or established pregnancy are discussed. Results show the maximum that can be spent to get specific cows pregnant.

\section{Economic Estimates from the Literature}

Realistic economic benefits of improved reproductive performance are not simple to estimate. When reproductive performance improves, all changes in cash flows that result from the improvement must be accounted for. So for a good

1. This document is AN156, one of a series of the Department of Animal Sciences, Florida Cooperative Extension Service, Institute of Food and Agricultural Sciences, University of Florida. Published August 2005. Please visit the EDIS Web Site at http://edis.ifas.ufl.edu.

2. Albert de Vries, Assistant Professor; Jessika van Leeuwen, Intern Graduate Student; William W. Thatcher, Graduate Research Professor; Department of Animal Sciences, University of Florida, Institute of Food and Agricultural Sciences, Cooperative Extension Service, Gainesville, 32611. 


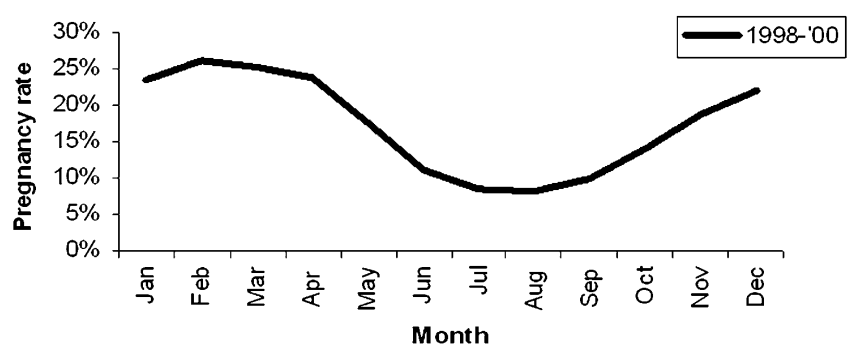

Figure 1. Average pregnancy rates in 1998-2000 of all Florida and Georgia Holstein herds that submit data to DHIA.

analysis, we need at least realistic estimates of lactation curves, feed intake, the risk of involuntary culling, and prices such as for milk, feed, labor, semen, fertility drugs, calves, replacement heifers and cull cows.

Cows that become pregnant faster will spend on average more time in the early part of the lactation (higher milk sales) and are less at risk to be culled for reproductive failure. But they are also more days dry per year and more often at risk for involuntary culling due to fresh cow problems. Furthermore, the voluntary culling policy can have a significant economic effect (how long to keep breeding open cows). In addition, the performance of replacement heifers should be included in the analysis.

For these reasons, researchers have built and used computer programs or spreadsheets to integrate the effects of all these different factors and come up with the best possible economic estimates of improved reproductive performance. Still, the economic estimates of improved reproductive performance from these studies differ due to variations in prices, lactation curves and feed intake, the risk of involuntary culling, insemination and voluntary culling policy, and method of calculation.

Some studies evaluated reproductive performance by estimating the additional cost per day open, expressed per cow per year. For example, Plaizier and coworkers ${ }^{(5)}$ reviewed the literature and found the average cost of a one-day-longer calving interval (one additional day open) to range from $-\$ 0.29$ to $\$ 2.60$. Their own estimate was a cost of approximately $\$ 3.36$ per extra day (1997 US dollars). Among many factors, the cost per extra day open depends on the actual days open. Using their spreadsheet model, French and Nebel ${ }^{(2)}$ estimated the cost of an additional day open from $\$ 0.42$ at 100 days open to $\$ 4.95$ at 175 days open (2003 US dollars). Thus, the cost per extra day open increases when cows are on average longer in milk.

Other studies looked at the value of a marginal increase in estrus detection rate, conception rate, or pregnancy rate. Marsh and coworkers ${ }^{(3)}$ found the value of a 1-percentage-point increase in estrus detection rate (e.g. from $40 \%$ to $41 \%$ ) to range from $\$ 1.15$ to $\$ 1.66$ and the value of a 1-percentage-point increase in conception rate to be $\$ 1.92$ to $\$ 2.61$ per cow per year using four different culling and rebreeding policies (1987 US dollars).

Pecsok and coworkers ${ }^{(4)}$ found that the value of a 1-percentage-point increase in pregnancy rate was worth about $\$ 0.86$ per cow per year when pregnancy rate was approximately 0.45 (1994 US dollars). At a lower pregnancy rate (13\%), a 1-percentage-point increase was worth approximately $\$ 16.60$. A decrease in the value of a marginal increase in pregnancy rate at higher pregnancy rates was also found by Risco and coworkers ${ }^{(7)}$ for conditions in Florida. The found no economic benefits from increasing pregnancy rate above $45 \%$.

Plaizier and coworkers ${ }^{(6)}$ studied the literature and found that values of a 1-percentage-point increase in estrus detection rate had been estimated from a loss of \$2 to a gain of more than \$16 (1998 US dollars). Their results also showed that improving poor reproductive performance was the most valuable.

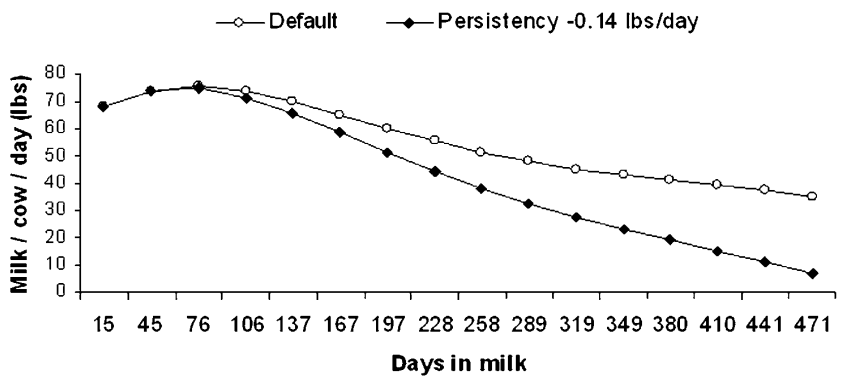

Figure 2. Lactation curves for second-lactation cows: Default situation (persistency $-0.07 \mathrm{lbs} /$ day) and a less persistent curve $(-0.14 \mathrm{lbs} /$ day). First-lactation curves are more persistent. Third and later lactation curves are less persistent. 


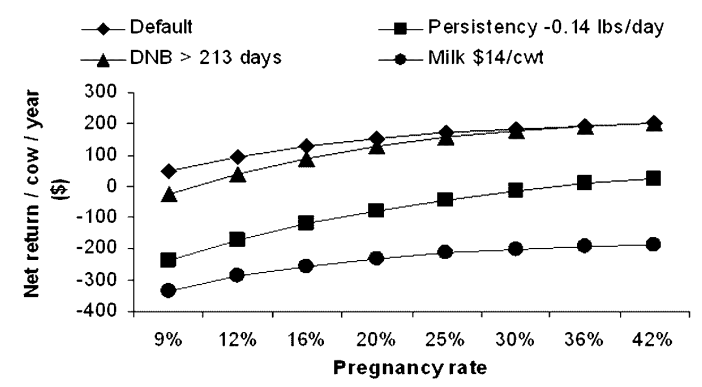

Figure 3. Effect of pregnancy rate on net return per cow per year for four situations.

\section{Florida Dairy Computer Program}

The Florida Dairy Computer Program is an advanced economic modeling computer program that allows users to evaluate the economic benefits of changes in dairy management. With it, the economic value of improvements in reproductive performance can be calculated. There are many inputs that the user can change. For example, the user can enter and change lactation curves, body weights, estrus detection and conception rates, the risk of voluntary culling, labor, feed intake and many prices such as for milk, feed, sold calves, purchased heifers, culled cows, labor, veterinary expenses, semen and fertility drugs. The program assumes that culled cows are replaced with purchased heifers. The voluntary culling policy is economically optimal, based on a cow's milk production, lactation number, days in milk, and pregnancy status. Cows can be bred between 60 and a maximum of 456 days (15 months) in milk (if not culled earlier), or they can be designated do-not-breed (DNB) earlier in lactation. Optimal voluntary delay of first breeding of individual cows is not considered in this paper, but is possible with the computer program. Lactation curves, reproductive inputs, and the risk of involuntary culling can be entered for each of 12 months of the year to mimic seasonal conditions.

After the inputs are determined, the computer program simulates a herd of cows over time and calculates resulting herd statistics such as average days open, cull rates, and various costs and returns per cow per year and per cwt milk produced. In the default situation, we assumed a milk price of $\$ 16$ / cwt, a calf price of $\$ 112.5$, a cull price of $\$ 0.36$ per lbs of body weight, and a heifer price of $\$ 1400$. Bodyweight and feed intake were taken from the
2001 NRC recommendations. Lactation curves were estimated from Florida and Georgia DHIA data for first, second, and later lactation cows. The default situation also assumed visual estrus detection with a $40 \%$ estrus detection rate and a $40 \%$ conception rate, resulting in a $16 \%$ pregnancy rate for all cows. Labor cost for open cows eligible to be bred was set at $\$ 18.24$ per cow per month, based on 0.6 minutes visual estrus detection per cow per day and a $\$ 10$ per hour labor cost. Direct cost per insemination was $\$ 10.83$, including semen and labor. Open cows were eligible to be bred up to 456 days in milk if not involuntary or voluntary culled earlier in lactation. Voluntary waiting period was 60 days. The length of the dry period was two months.

With the default inputs, Table 1 shows the resulting cost and revenues per cow per year and per cwt and some herd statistics. These results are in agreement with routinely collected financial data on Florida and Georgia dairies ${ }^{(1)}$. Breeding supply costs include the cost of semen only. Total cost per pregnancy included cost for semen and labor for breeding and visual estrus detection.

\section{Economic Value of a Change in Pregnancy Rate}

The Florida Dairy Computer Program was used to evaluate the economic effects of a change in pregnancy rate. Estrus detection rate and conception rate were simultaneously varied from $30 \%$ to $65 \%$ with increments of $5 \%$. This resulted in pregnancy rates from $9 \%(30 \% * 30 \%)$ to $42.2 \%(65 \% *$ $65 \%)$.

The effects of changes in pregnancy rates were evaluated for four situations:

1)Default inputs: milk price $\$ 16$ / cwt, DNB > 456 days open, and a default lactation curve persistency -0.07 lbs/day (see Figure 2).

2)Lower milk price: milk price $\$ 14$ / cwt.

3)No breeding later in lactation: DNB > 213 days open (7 months in milk).

4)Less persistent lactation curves: $-0.14 \mathrm{lbs} /$ day, see Figure 2. 
Table 1. Herd statistics in the default situation.

\begin{tabular}{lcccr}
\hline Variable & Per cow $/ \mathrm{yr}$ & Per cwt & Variable & \\
\hline milk sales $(\$)$ & 3070 & 16.00 & milk:feed price ratio & 2.18 \\
cow sales $(\$)$ & 156 & 0.81 & fixed:total cost ratio & 0.20 \\
calf sales $(\$)$ & 119 & 0.62 & calving interval (days) & 410 \\
total revenue $(\$)$ & 3345 & 17.43 & days to conception & 135 \\
feed cost $(\$)$ & 1411 & 7.35 & pregnancy rate & $16 \%$ \\
breeding supply cost $(\$)$ & 21 & 0.11 & overall cull rate & $32 \%$ \\
heifer purchase cost $(\$)$ & 450 & 2.34 & involuntary cull rate & $24 \%$ \\
veterinary cost $(\$)$ & 81 & 0.42 & voluntary cull rate & $8 \%$ \\
variable labor cost $(\$)$ & 433 & 2.26 & milk / cow / yr (lbs) & 19,185 \\
variable other cost $(\$)$ & 182 & 0.95 & total cost / pregnancy $(\$)$ & 40 \\
fixed cost $(\$)$ & 638 & 3.33 & & \\
total costs $(\$)$ & 3217 & 16.76 & & \\
net revenue $(\$)$ & 128 & 0.67 & & \\
\hline
\end{tabular}

Figure 3 shows how higher pregnancy rates increase the net return per cow per year for the four situations. The less persistent lactation curves and the $\$ 14$ milk price result in negative net return per cow per year. The change in net return per cow per year per 1 percentage point increase in pregnancy rate (e.g. from 20\% to 21\%) is shown in Figure 4. This is the slope of Figure 3.

Figure 4 confirms results from the literature review that the economic value of a marginal increase in pregnancy rate becomes smaller when pregnancy rates are higher. The highest value at a change in pregnancy rate from $11 \%$ to $12 \%$ is approximately \$20 for the situations with the lower persistent lactation curves and do-not-breed open cows after 213 days. The increase is then most valuable because additional days open are very costly in these situations: cows later in milk produce increasingly less milk and open cows have less chance to get pregnant before 213 days in milk are reached. Both lead to increased culling of open cows and thus higher replacement costs.

Higher pregnancy rates lead to lower average days to conception as can be seen in Figure 5. At a $9 \%$ pregnancy rate, the differences in average days to conception between the four situations are the largest. The two situations which are least favorable later in lactation (lower persistency and DNB > 213 days open) result in the lowest days to conception (144 and 123 days respectively). This looks good but it is not. The reason is that open cows in these situations will not remain in the herd late in lactation but get culled, whereas in the other situations more open cows can still get pregnant later in lactation and thus add to a higher average days to conception.

In general, days to conception decrease when the pregnancy rate increases. Average days to conception at $42.2 \%$ pregnancy rate are very similar for all four situations because most cows get pregnant quickly after the voluntary waiting period, regardless of a lower persistent lactation curve or less breeding opportunity later in lactation.

The cost per extra day open varies from $\$ 0.81$ to $\$ 13.33$ and increases with higher days to conception (Figure 6). As economic conditions later in lactation worsen (lower persistency and no breeding opportunities after 213 days in milk), the cost per extra day open increases. The later in lactation an open cow is, the greater the risk that she will be culled. Milk price has little effect on the cost of an extra day open.

\section{Economic Value of an Increase in First Service Pregnancy Rates}

Several reproductive programs focus on improving pregnancy rates of the first ovulation after the voluntary waiting period. To mimic this situation, we set the estrus detection rate to $100 \%$ for the first estrous cycle after the voluntary waiting period. All other inputs remained the same: conception rate 


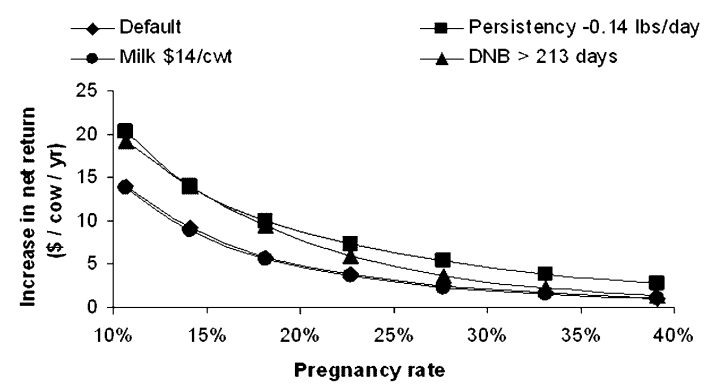

Figure 4. Effect of a 1-percentage-point increase in pregnancy rate (e.g. from $20 \%$ to $21 \%$ ) on the increase in net return per cow per year for four situations.

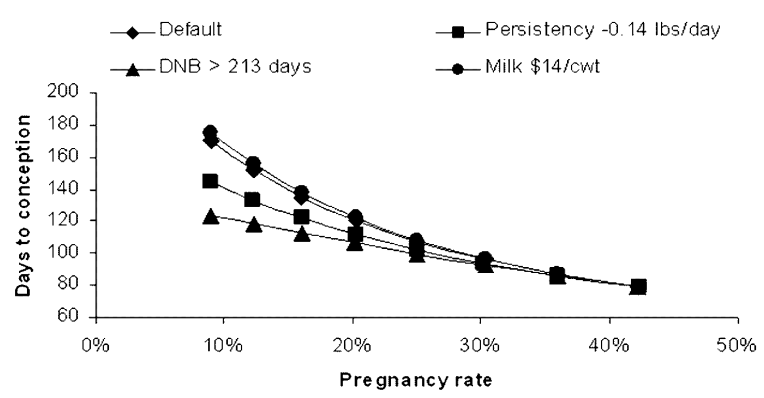

Figure 5. Effect of pregnancy rate on days open for four situations.

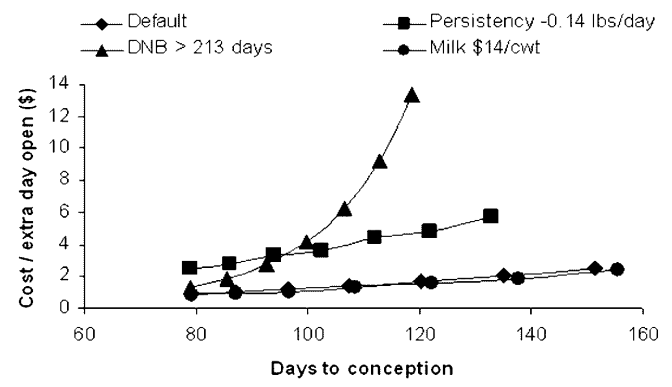

Figure 6. Effect of average days open on cost per extra day open for four situations.

remained at $40 \%$ and estrus detection rate after the first cycle remained at $40 \%$.

Table 2 shows that the net return per cow per year increased from $\$ 17.93$ to $\$ 51.14$. The greatest benefits were for the two situations which are the least favorable for cows in late lactation (lower persistency and DNB past 213 days).

A break-even cost was calculated, which is the maximum extra expense per open cow in her first month after the voluntary waiting period to keep the $100 \%$ estrus detection rate more profitable than the $40 \%$ estrus detection rate. For the default situation, up to $\$ 18.56$ could be spent on improving estrus detection rate from $40 \%$ to $100 \%$ before the $\$ 147.35$ is reduced to $\$ 127.64$. If the persistency of milk production is lower, then up to $\$ 45.83$ could be spent because it is even more important to get cows pregnant early in lactation. The break-even costs are similar to the difference in net return per cow per year because cows have on average approximately one first estrous cycle per year.

These break-even cost estimates also apply to a timed AI program with a $40 \%$ conception rate and no estrus detection. The break-even cost plus the labor savings because no estrus detection is required need to be greater than the fertility drug and labor cost of the timed AI program.

\section{Economic Value of a Pregnancy}

The analyses above show the economic benefits of increasing herd pregnancy rate and the cost of an extra day open to the dairy. It is also clear that the average maximum expenditure per open cow to improve first service pregnancy rate is very similar to the increase in net return per cow per year when first pregnancy rate is improved. However, the maximum that can be spent to get a cow pregnant is not the same for each open cow.

The economic value of a pregnancy is the difference in all expected future net returns from two identical cows, one pregnant, and the other one open. One way to calculate the economic value of a pregnancy is to compare the Retention Pay-Off (RPO), also called future profitability or cow value, of the two cows. The RPO of a cow is the difference in expected total net returns from trying to keep the cow until her optimal time of voluntary replacement (including the risk of involuntary culling) compared to immediately culling her now and replacing her with a heifer ${ }^{(8)}$. A cow's RPO changes over time and depends on her lactation number, level of milk production, days in milk, and pregnancy status. If cow performance is seasonal, RPO also depends on the season. The RPO can be used to rank cows for future profitability and help make culling decisions (an RPO < \$0 suggests that the cow should be replaced as soon as possible with a heifer. In fact, a cow is culled voluntary in the Florida Dairy Computer Program when her RPO drops below \$0). The average RPO of all cows in the herd at any time 
Table 2. Net return per cow per year with a $100 \%$ and $40 \%$ estrus detection rate in the first estrous cycle after the 60 day voluntary waiting period, and break-even cost.

\begin{tabular}{|c|c|c|c|c|}
\hline \multirow[b]{2}{*}{ Situation } & \multicolumn{3}{|c|}{ Net return / cow / year $(\$)$} & \multirow[b]{2}{*}{ Break-even $^{1}$} \\
\hline & $\begin{array}{l}100 \% \text { Estrus } \\
\text { detection rate }\end{array}$ & $\begin{array}{l}40 \% \text { Estrus } \\
\text { detection rate }\end{array}$ & Difference & \\
\hline Default & 147.35 & 127.64 & 19.71 & 18.56 \\
\hline Persistency -0.14 lbs/day & -69.35 & -120.49 & 51.14 & 45.83 \\
\hline DNB $>213$ days open & 123.18 & 89.95 & 33.23 & 30.20 \\
\hline Milk price $\$ 14 / c w t$ & -237.27 & -255.20 & 17.93 & 17.08 \\
\hline
\end{tabular}

${ }^{1}$ Break-even $=$ maximum to be spent on a reproductive program in the first month after the voluntary waiting period per eligible open cow.

in the default situation is $\$ 607$. The RPO plus the slaughter value (about \$400) equals the market value of the average cow in the herd (about $\$ 1000$ ).

Figure 7 shows the effect of days in milk on the RPO of two cows in their second lactation. One cow is still open after 300 days in milk and the other cow becomes pregnant on day 61 in lactation. The RPO of the open cow decreases over time and around 300 days in milk she gets near the point where replacing her becomes the more profitable decision (RPO \$0). The economic value of the new pregnancy at day 61 is the difference in their RPOs: $\$ 934-\$ 793=\$ 141$. This also represents the amount that could be spent to get this cow pregnant at that time in her lactation. The RPO of the pregnant cow decreases for a while because she is still at risk for involuntary culling due to mastitis, death, feet and leg problems etc. before the next calving. However, the value of the pregnancy increases with the length of the pregnancy because it becomes more likely that she will actually calve and make it to the third lactation. The value of the eight-month-old pregnancy at 300 days in milk compared to the open cow at 300 days in milk is $\$ 720$.

The value of establishing a new pregnancy later in lactation increases up to $\$ 238$ at nine months in milk (243 days), but then decreases again (Figure 8). If cows are open very late in lactation, and if they produce less milk, as is expected by the lactation curve, the difference between replacing the open cow and keeping the new pregnant cow becomes smaller. The advantage of getting the cow pregnant is lower because she would spend the next seven months of her life producing not much milk (we did not consider early dry off), compared to replacing the open cow and bringing in an average-producing fresh heifer.
The value of the new pregnancy later in lactation is greater if cows are more persistent (Figure 8, first lactation cows). We assumed that first-lactation cows were more persistent than older cows. On the other hand, the value of a new pregnancy early in lactation is smaller for more persistent cows and when pregnancy rate is higher. The average value of a new pregnancy in the herd was $\$ 85$ in the default situation, \$154 when milk persistency was $-0.14 \mathrm{lbs} /$ day, $\$ 105$ when DNB > 213 days open, and $\$ 79$ when milk price was $\$ 14$ / cwt.

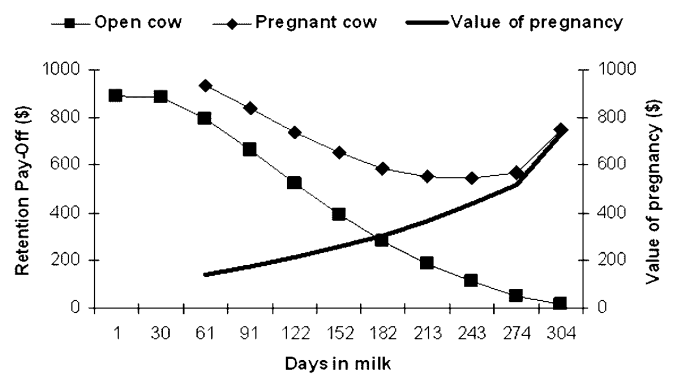

Figure 7. Retention Pay-Off (RPO) for two average second-lactation cows: One cow does not become pregnant; the other cow becomes pregnant at 61 days in milk. The difference in the RPO is the value of the pregnancy.

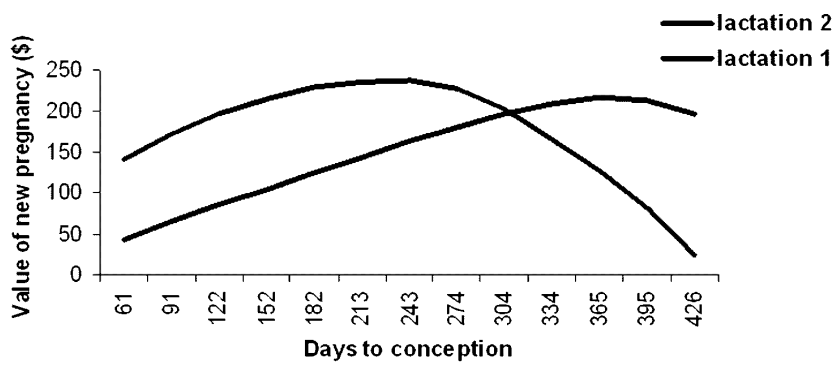

Figure 8. The effect of days to conception on the value of a new pregnancy for first- and second-lactation cows in the default situation. First-lactation cows have more persistent lactation curves than cows in their second lactation. 


\section{Literature Cited}

1. de Vries, A., R. Giesy, L. Ely, A. de Araujo, A. Andreasen, B. Broaddus, S. Eubanks, D. Mayo, P. Miller, T. Seawright, and C. Vann. 2003.

Dairy Business Analysis Project: Financial Summary for 1995-2001. UF/IFAS Extension Document DS174. Available on http://edis.ifas.ufl.edu/DS174.

2. French, P. D. and R. L. Nebel. 2003. The simulated economic cost of extended calving intervals in dairy herds and comparison of reproductive management programs. Journal of Dairy Science 86 (Suppl. 1):54 (abstract).

3. Marsh, T. G., R. S. Morris, and A. A. Dijkhuizen. 1985. An economic comparison of four culling decision rules for reproductive failure in the US dairy herds using Dairy ORACLE. Journal of Dairy Science 70:1274-1280.

4. Pecsok, S. R., M. L. McGilliard, and R. L. Nebel. 1994. Conception rates: Derivation and estimates for effects of estrus detection on cow profitability. Journal of Dairy Science 77:3008-3015.

5. Plaizier, J. C. B., G. J. King, J. C. M. Dekkers, and K. Lissemore. 1997. Estimation of economic values of indices for reproductive performance in dairy herds using computer simulation. Journal of Dairy Science 80: 2775-2783.

6. Plaizier, J. C. B., G. J. King, J. C. M. Dekkers, and K. Lissemore. 1998. Modeling the relationship between reproductive performance and net-revenue in dairy herds. Agricultural Systems 56: 305-322.

7. Risco, C. A., F. Moreira, M. DeLorenzo and W. W. Thatcher. 1998. Timed artificial insemination in dairy cattle - part II. The Compendium on Continuing Education for the Practicing Veterinarian 20: 1284-1289.

8. van Arendonk, J. A. M. 1984. Studies on the replacement policies in dairy cattle. I. Evaluation of techniques to determine the optimum time for replacement and to rank cows on future profitability. Zeitschrift fuer Tierzuechtung and Zuechtungsbiologie 101: 330-340. 